\title{
Effects of Seductive Details on Multimedia Learning
}

\author{
Zhe Wang \\ Department of Educational Leadership \\ Sport Studies, \& Educational/Counseling Psychology \\ College of Education, Washington State University, Pullman, U.S.A. \\ Tel: 1-509-338-5671_E-mail: zhe.wang2@wsu.edu
}

Olusola O. Adesope

Department of Educational Leadership

Sport Studies, \& Educational/Counseling Psychology

College of Education, Washington State University, Pullman, U.S.A.

Tel: 1-509-335-2771Ｅ-mail: olusola.adesope@wsu.edu

Received: July 24, 2014 Accepted: August 11, 2014 Published: August 11, 2014

doi:10.5296/jse.v4i3.6024

URL: http://dx.doi.org/10.5296/jse.v4i3.6024

\begin{abstract}
Multimedia learning involved learning with multiple media (e.g., text, pictures, video). In an experiment examining the seductive details effect of multimedia learning, 78 participants recruited from a middle school in China were randomly assigned to study one of three learning materials (no seductive details, seductive details at the beginning, and seductive details at the end) about the economic situation in a particular state in the U.S. On a test of free recall, the no-seductive-details group recalled significantly more main idea than either the group that studied with seductive-details-first or the group that studied with seductive-details-after. However, the seductive-details-first group and the seductive-details-after group did not differ significantly. When recall of seductive details was specifically examined, the seductive-details-first group recalled significantly more seductive details than the seductive-details-after group. The results indicate that seductive details interfere with learning by distracting the reader. The results are discussed and implications for practice are delineated.
\end{abstract}

Keywords: Seductive details, Social science, Natural science, Multimedia 


\section{Introduction}

Researchers have used the term seductive details to refer to interesting but irrelevant information that is added to a passage with the intended goal of making it more interesting and attractive (Garner, Brown, Sanders, \& Menke, 1992; Garner, Gillingham, \& White, 1989). Succinctly, seductive details entail inclusion of information that is irrelevant to the text's main ideas, the instructional goal, or the author's intended theme. This study is part of a research program that investigates the effects of seductive details in the social sciences. The overarching goal of this study was to examine three dominant hypotheses about the seductive details effect in the social sciences. Specifically, this study attempts to clarify how seductive details influence learning in the social sciences depending on when such seductive details are presented.

Teachers, instructional designers, and textbook authors in different fields have introduced seductive details in a bid to make learning materials more interesting and captivating to the learners. One key explanation for using seductive details has always been that such seductive presentations might arouse learners' interest and result in active learning, higher-rate recall, deeper processing, and better learning and transfer (Towler et al., 2008). Similarly, material that is interesting is thought to energize the learner toward encoding information from the learning materials (Izard \& Ackerman, 2000; Kintsch, 1980). However, the taken-for-granted rationale behind adding interesting yet tangential information has been questioned by many researchers (e.g., Harp \& Mayer, 1997; Harp \& Mayer, 1998; Moreno \& Mayer, 2000). The debate between seductive details as beneficial or inhibiting for learning is still continuing. This study is the first in a series of planned studies to explicate the effects of different forms of seductive details on learning.

\section{Literature Review}

"Multimedia learning occurs when people build mental representations from words and pictures” (Mayer, 2005, p.2). With the upsurge of interest in multimedia learning, numerous theories have emerged making an attempt to broaden our understanding of learning from multimedia presentations. In multimedia learning research, Mayer's (2005) coherence principle predicts that seductive details (additional irrelevant information), even when interesting, may cause distraction or impose extraneous cognitive load on students (Mayer, 2005). In a study that used lightning formation as a topic, Harp and Mayer (1998) found that students in the no-seductive-details group recalled significantly more relevant idea units and performed significantly better on a transfer test than did the other three groups (base-plus-seductive-text group, base-plus-seductive-illustrations group, and base-plus-seductive-text-and-seductive-illustrations group). In another study, Moreno and Mayer (2000) found that participants that received added background music and/or sounds performed worse than participants that received no added information on tests of retention and transfer. More recently, Mayer, Griffith, Jurkowitz, and Rothman (2008) conducted two experiments and found that adding high-interest details to a PowerPoint lesson (how a cold virus infects the human body and how digestion works) resulted in poorer transfer test performance than adding low-interest details. Both groups performed similarly on retention 
tests. Garner, Gillingham, and White (1989) carried out two experiments and contended that seductive details can disrupt macroprocessing (the recall task) even for skilled adult reader and influence negatively on both macroprocessing and microprocessing (the picture matching task) for seventh graders.

Harp and Mayer (1998) listed three plausible theoretical explanations for the seductive details effect: the distraction hypothesis, the disruption hypothesis, and the diversion hypothesis. The distraction hypothesis predicts that seductive details do their damage by drawing the reader's selective attention away from important information; the disruption hypothesis predicts that seductive details are damaging because they interrupt the transition from one main idea to the next; while the diversion hypothesis predicts that the reader builds a representation of the text organized around the seductive details, rather than around the important main ideas contained in the lesson. Their results showed that only the diversion hypothesis provided sufficient explanations for seductive details effect. In other words, the finding suggested that seductive details interfere with learning by priming inappropriate schemas around which readers organize the material.

However, the boundaries that are used to distinguish the three hypotheses proposed by Harp and Mayer (1998) are not as apparent as initially advanced. For example, interestingness of seductive details (distraction) may cause the reader to allocate more attention and reading time to the seductive details believing that the important information is contained in the seductive details, hence leading to the construction of inappropriate schema (diversion). To extend Harp and Mayer's hypotheses, Lehman, Schraw, McCrudden, and Hartley (2007) developed three modified hypotheses, that is, the reduced attention hypothesis, the coherence break hypothesis, and the inappropriate schema hypothesis. More importantly, they employed two indicators, one of which is the effect on learning and the other is the effect on reading time, to test the different hypotheses. Consider the coherence break hypothesis for example. This hypothesis would be supported if reduced holistic understanding of base text occurs and if reading rate slows down on the transition from seductive details back to base text. Although Harp and Mayer (1998) had proposed that the diversion hypothesis was the most likely explanation for seductive details affecting the learning process, Wiley (2003) demonstrated that presenting images before a text reduced the negative impact of seductive imagery. Wright, Milroy, and Lickorish (1999) found that presenting animation before a text also reduced any detrimental effect to learning performance, when compared with embedded animation within a text.

However, in both Wiley's and Wright's cases delineated above, all the seductive details used were images or animation rather than texts. Schnotz and Bannert (2003) proposed a theoretical framework for analyzing text and picture comprehension and differentiated verbal channel from pictorial channel. Also, Al-Seghayer (2001) found that video with text presentations was more beneficial to learners than still picture with text presentations and text alone in terms of second-language vocabulary learning. Given that the processing mechanism for words is different than that for pictures and/or animations, it be may be that the diversion hypothesis may be supported when seductive details are included first as texts before the students are required to read the main passage. 
The Working Memory and Controlled Attention Theory (WMC) offers another important theoretical explanation for seductive details effect. WMC suggests that it is the ability to ignore irrelevant information not the amount of available working memory that can account for individual differences (Conway \& Engle, 1994; Kane, Bleckley, Conway, \& Engle, 2001). Therefore, an important prerequisite for students to solve a problem in the field of natural science is to reduce extraneous cognitive load during instruction to free up resources for learning by minimizing or even eradicating seductive details (Muller, Sharma, \& Reimann, 2008). In Sanchez and Wiley's (2006) study, a group of undergraduates were assigned an essay response and an inference verification task. The researchers found that high-WMC individuals were not as susceptible to the seductive details effect as the low-WMC.

Similarly, cognitive load theory (Paas, Renkl, \& Sweller, 2003) assumes that knowledge acquisition depends on the efficiency of the use of available (limited) cognitive resources, which leaves us a critical question: does cognitive load moderate the seductive details effect? Park, Moreno, Seufert, and Brunken (2010) conducted a study and concluded that "the cognitive processes of selecting relevant information and organizing this information into a coherent mental model can be affected not only in a negative way by seductive details, but also in a positive way if learners have enough resources free to use this non-redundant and interesting, but irrelevant learning material” (p. 9).

The effect of seductive details might operate differently when dealing with different subjects. Most previous research on seductive details focused on learning about complex systems (e.g., lightning), while a few studies did not. In one of such studies, Towler et al. (2008) focused on learning procedural skills in software programs and found no negative effect for seductive details on recognition tests and a beneficial effect on transfer performance. In another study, Shen, McCaughtry, Martin, and Dillion (2006) examined the effect of seductive details on students' learning of net games in physical education. They found that seductive details directly interrupted students' recall of important learning content and problem-solving transfer in learning net games.

Besides, we observed that the process of lighting is the dominant subject in many seductive details research. For example, Mayer and his research associates conducted 11 experiments on seductive details, 10 of which were on lightning and 1 on brakes (Mayer, 2005). Even in studies conducted by other scholars examining the seductive details effect or the diversion hypothesis, lightning has been a dominant topic. Harp and Maslich (2005) designed an experiment in which students listened to a recorded lecture about lightning that either contained or did not contain seductive details. In another study, McCrudden and Corkill (2010) examined the influence of seductive details sentences on reading time and recall for readers with higher and lower verbal ability using the text on lightning (how it forms and under which conditions it occurs). While we appreciate lightning as an important topic in the natural sciences, the dominant emphasis on lighting significantly limits researchers' understanding of the effect of seductive details in other domains, especially in non-natural sciences. Specifically, researchers have limited understanding of how seductive details will influence learning in the social science topics. 
As Kuhn puts it, overall, research in the natural sciences appears more orderly than in the social sciences or education (Kuhn, 1996). Although we acknowledge that there are some commonalities between the two fields, however, we claim that there are vastly different philosophical distinction, topical issues and learning strategies between natural sciences and social sciences. Therefore, the rationale that using emotional interest adjuncts, such as seductive text and seductive illustrations disrupts the reader's construction of the cause-and-effect chain (the disruption hypothesis) may operate differently from natural sciences to social sciences. For example, the cause-and-effect chain in the social sciences is perceived in a vastly different way than in the natural sciences. The construction of the former depends, if not totally, at least in large part, on the ability of imagination and the tendency to look at things from an overall perspective, while the construction of the latter relies mostly on precise understanding of unchangeable formulas and reasonably fixed rules of our physical world. From at least the time of Descartes, the physical and life sciences adopted and benefited from the simplifying methods of rational analysis, empirical specification, and reductionism that allowed researchers to tease out testable models of nature (Eisenhart \& Dehaan, 2005). However, the complexity of social sciences lies in, "first, the highly nonlinear, non-stationary, and adaptive nature of social sciences themselves and, second, their non-homogeneous and massive parallel patterns of interconnections" (Koch \& Laurent, 1999, p. 98). Indeed, Mayer (2001) claimed that "there can be alternative theories to explain the same phenomenon and educational research often requires the ability to tolerate ambiguity" (p. 29). In multimedia learning, scholars have been aware of the distinction between the social sciences and the natural sciences and carried out studies questioning the generalizability of basic principles that build on the context of the natural sciences. For example, De Westelinck, Valcke, De Craene, and Kirschner (2005) examined the multimedia principle using materials about learning styles rather than materials in the domain of the natural sciences and found that studying text without external graphical representations sometimes results in higher performance. This result contradicts original cognitive theory of multimedia learning hypothesis. Inspired by their research, the rationale that inappropriate prior knowledge would be activated by seductive details (the diversion hypothesis) may be questionable as well. Seductive details, thought to activate inappropriate prior knowledge in the context of learning the formation of lightning according to the viewpoint of Harp and Mayer, in most cases, may not be in conflict with important information. Even with the presence of seductive details in a passage about social sciences, student learning may not be hurt by relating the passage with prior knowledge.

Although it has been shown that the diversion hypothesis has the most explanatory value in the natural sciences, it would be premature if we extended the conclusion to the social sciences without corresponding experiments backing them up. Hence, the present research seeks to understand the effect of seductive details on learning materials in the social sciences by focusing on testing the three aforementioned hypotheses.

\subsection{Research questions}

In considering the findings from extant research, the present experiment was designed to address two key research questions: 
(1) Are seductive details deleterious in the context of social sciences learning; and

(2) What mechanism may account for seductive details effect in social sciences: the distraction, disruption, or diversion hypothesis?

\section{Method}

\subsection{Participants and Research Design}

The participants were 78 students (61 females and 17 males) recruited from a middle school in China. The average age of participants was 15 years. The participants were randomly assigned to three groups. Using a between-subjects design, one group of participants read a passage with no seductive details, another group with seductive details presented at the beginning of the passage, and the last group with seductive details presented at the end of the passage. There were 27 students in the first group (no-seductive-details), 25 in the second group (seductive-details-first group), and 26 in the last group (seductive-details-after).

\subsection{Materials}

The subjects read an expository and narrative text on the topic of economic situation and prospects in a particular state in the United States. The base text (the passage with no seductive details) was approximately 910 Chinese characters long and the seductive text was approximately 730 characters long. In addition, two captioned color photographs were inserted throughout the seductive text as a supplementary to make the passage highly interesting. The seductive text was tangentially related to the topic for the reason that on one hand, it described certain interesting places in the state and presented a short story about the state, and on the other hand, it carried no weights in establishing a relationship with the critical part of the topic, which was the current economic situation of the state. In order to increase the interestingness of the multimedia seductive details, we inserted two pictures that can be considered the embodiments of the representative features of the state accompanied by the words. After the subjects had finished reading the seductive material, they were then required to start the recall task in a piece of blank paper.

\subsection{Procedure}

The experiment was conducted in a middle school classroom. Each participant was engaged for approximately 30 minutes. First, all participants provided background information and were then assigned to one of three groups (no seductive details, seductive details at the beginning, and seductive details at the end). The participants in the no-seductive-details group studied the base passage about economy within 10 minutes. In other words, they studied the passage without any seductive details. After that, the booklets where the passage was presented were collected and each participant was given a recall sheet. They were told that they would have 5 minutes to write down everything they could remember from the passage. The recall sheets were collected after 5 minutes. The procedures were the same for the other two groups as the first group, except that the seductive-details-first group read the passage with the seductive details presented at the beginning and the seductive-details-after group read the passage with the seductive details at the end. 


\section{Results}

The recall score for the main passage was determined by assigning 1 point for each idea unit presented in the passage that the participant was able to correctly recall. The recall score of the seductive details was determined similarly. Prior to data analysis, all variables were examined for accuracy of data entry, outliers and normality of distributions. No outliers were detected. Distributions were normal and within acceptable levels of skewness and kurtosis (Tabachnick \& Fidell, 2006). One point was assigned for each correctly-recalled response from the passage. No point was assigned when the recalled information was incorrect or different from the material studied. Table 1 shows the main idea free recall means, standard deviation, and sample size for each of the treatment groups. A one-way ANOVA revealed a statistically significant difference in the number of non-seductive idea units recalled among the three groups, $F(2,75)=52.15, M S E=91.97, p<.001, \eta_{p}^{2}=.58$, indicating a large effect size $(d=.76)$ and that $58 \%$ of free recall variance could be attributed to treatment. Using Tukey's honestly significant difference (HSD) test with alpha less than .05, it was found that students who read the no-seductive passage recalled significantly more main idea than did either the group who read the seductive-details-first passage or the seductive-details-after passage. However, the seductive-details-first group and the seductive-details-after group did not differ significantly $(p>.05)$. This finding is inconsistent with the diversion hypothesis.

Table 1. Main Idea Free Recall Performance of the Three Treatment Groups

\begin{tabular}{lccc}
\hline Treatment & Mean & SD & \multicolumn{2}{c}{$\mathrm{N}$} \\
& & & \\
\hline No-seductive details & 4.48 & 1.19 & 27 \\
Seductive-details-first & 1.20 & 1.41 & 25 \\
Seductive details-after & 1.31 & 1.38 & 26 \\
\hline Pooled & 2.37 & 1.33 & 78 \\
\hline
\end{tabular}

A one-way ANOVA revealed that there was a significant difference in the number of seductive idea units recalled between the seductive-details-first and the seductive-details-after group, $F(1,49)=97.48, M S E=218.36, p<.001, \eta_{p}^{2}=.72$, indicating a large effect size $(d$ $=.85$ ) and that $72 \%$ of free recall variance could be attributed to treatment. A Tukey's HSD test showed that students who read the seductive-details-first passage recalled significantly more seductive details than those who read the seductive-details-after passage. 
Table 2. Seductive Details Recall Performance

\begin{tabular}{lccc}
\hline Treatment & Mean & \multicolumn{1}{l}{ SD } & N \\
\hline No-seductive details & N/A & N/A & 27 \\
Seductive-details-first & 5.60 & 1.98 & 25 \\
Seductive details-after & 4.00 & 1.72 & 26 \\
\hline Pooled & 4.78 & 1.85 & 78 \\
\hline
\end{tabular}

\section{Discussion}

This experiment examined the seductive details effect with middle school students in China who learned with one of three materials (no seductive details, seductive details at the beginning, and seductive details at the end) about the economic situation in a particular state in the U.S. In the present study, the no-seductive group recalled more main ideas than the seductive-details-first and the seductive-details-after group. This finding is supportive of the Principle of Coherence (Mayer, 2005), that is, when the purpose of a presentation, is to instruct, designers should only include on the material what is absolutely necessary for the learners to understand the material. Extraneous seductive materials that are irrelevant to the learning goal will result in incoherence and thus be deleterious to learning.

Also, given that the reading material used in this study is about general economic situation that the students were not familiar with; the effect of disruption hypothesis may be ruled out. The major reason is that unlike the lightning material used by Harp and Mayer $(1997,1998)$, there were significantly fewer causal links in the economic passage used in the present study. In other words, links between different parts in the passage about economy are not as obvious as those in passages about natural sciences such as lightning. For example, consider an apparent causal chain between "warm air rises" and "condenses and forms a cloud" in the lightning passage. However, in the economic passage used in the present study, fewer such causal chains exist.

Another reason to exclude the disruption hypothesis is evident by the seductive details that were not interspersed throughout the passage in the present study. The disruption effect, would be minimized because the seductive details were separated from the base text. Specifically, the links between the steps in the causal chain which might be interrupted by the seductive details would be retrieved when the reader focused on the base text. If the seductive details, however, were spread throughout the passage, the frequent export of seductive details that could otherwise occur in the event of the seductive details intertwining with the non-seductive text and thus might result in disruption.

The results did not show any significant differences between the seductive-details-first group and the seductive-details-after group relative to the number of main idea units recalled. Two possible explanations could be offered for the results. Given that the two interventions did not 
produce differential results in free recall outcome measure, it suggests that placing the seductive details at the beginning of the passage did not result in interference to schema acquisition of the main ideas in the base passage. In that case, the diversion hypothesis can be ruled out and the distraction hypothesis may be upheld. The alternative explanation is that the seductive-details-first-intervention might activate incorrect schema whereas the seductive-details-after-intervention might lead to distraction of the free recall. In that case, the seductive details might undermine learning in different ways depending on their varying positions. The results of the experiment and the nature of the passage about general economy indicate that the seductive details effect does exist either in the natural sciences or social sciences. More importantly, this study offers evidence that the distraction hypothesis may provide a viable explanation in delineating the negative influence of seductive details used in passages of social sciences, that is, seductive details do their damage by "seducing" the readers' selective attention away from what they are supposed to focus on, especially when seductive details are presented at the end of a passage.

The results also indicate that the students who read the seductive-details-first passage recalled significantly more seductive details than those who read the seductive-details-after passage. This may be due to the possibility that the seductive details entering the students' working memory would be processed further in a short time and kept for a long time given the interesting nature of the seductive details. However, it is possible that for the other group that read the seductive-details-after passage, their working memory would not be overloaded with seductive details at the beginning. When they read the seductive details at the end of the passage, their attention would, at that point, be obstructed with the ongoing process of learning the main content.

\section{Conclusions}

Given that the distraction hypothesis is tenable in terms of interpreting the seductive details effect found in this study, the results suggest that the deleterious effects of seductive details in the social sciences can be minimized by avoiding or preventing learners from being distracted by irrelevant information. One way is to leave enough time between reading the main passage and the seductive details in order to minimize the distraction effect. Alternatively, we can set transitional paragraphs between seductive details and the base passage. Doing so may on one hand retain learners' interest and motivate them to read the base passage. On the other hand, it can transfer learners' attention gradually to the main content to minimize distraction. Another more direct approach would be to desist from introducing seductive details. Alternatively, if the seductive details effect operates differently when they are placed in different positions, which means the diversion hypothesis is supported when seductive details are presented at the beginning and the distraction hypothesis is supported when they are presented at the end, it would be better, in the situation that we have to use seductive details, to move them to the end. Doing so may be helpful because it would be more manageable and easier to moderate the distraction effect (e.g., leave enough time between reading the main passage and the seductive details) than the diversion effect. 
Another implication is that researchers should more carefully consider the possibility of carrying out follow-up studies based on these results. For example, considering the results of the present study on the effects of seductive details in social sciences may encourage further exploration of the seductive details effects, especially the specific conditions under which seductive details can enhance or inhibit learning. This may provide a platform under which theoretical underpinnings can be further enhanced. Future studies should continue to examine not only seductive details effect but other multimedia principles with the goal of advancing the theoretical and empirical rationales for their effectiveness.

One primary limitation is the failure to use multiple dependent measures. The only measure used in this study is the free recall. Considering that free recall measures typically may not adequately assess high order thinking and understanding, it is possible that transfer measures may produce somewhat different results. To address this, future research should develop and use other measures to assess students' learning objectively and comprehensively.

Second, time on task, (limit of 30 minutes in the present study) was not considered as a possible moderating factor. Although the seductive details effect was obvious, the strong effect might be caused partly due to the use of a strict time limit in the learning and test phases. In a recent meta-analysis of seductive details effect, Rey (2012) found that many seductive details studies typically contained 30 - 40\% additional information compared to control groups and stated that it is possible that, for learners receiving seductive details, they might have problems processing larger amounts of information within a constrained time. Hence, the results of the present study may be more subject to the total amount of information the seductive-details groups had to read rather than the nature of the seductive details. Future research may vary the nature or degree of seductive details to more thoroughly examine this hypothesis.

\section{References}

Al-Seghayer, K. (2001). The effect of multimedia annotation modes on L2 vocabulary acquisition: A comparative study. L Language Learning and Technology, 5, 202-232.

Conway, A. R. A., \& Engle, R. W. (1994). Working memory and retrieval: A resource-dependent inhibition model. Journal of Experimental Psychology: General, 123, 354-373.

De Westelinck, K., Valcke, M., De Craene, B., \& Kirschner, P. (2005). Multimedia learning in social sciences: Limitations of external graphical representations. Computers in Human Behavior, 21, 555-573. http://dx.doi.org/10.1016/j.chb.2004.10.030

Eisenhart, M. \& DeHaan, R. L. (2005). Doctoral preparation of scientifically based education researchers. Educational Research, 34, 3-13. http://dx.doi.org/10.3102/0013189x034004003

Garner, R., Brown, R., Sanders, S., \& Menke, D. (1992). "Seductive details" and learning from text. In K. A. Renninger, S. Hidi, \& A. Krapp (Eds.), The role of interest in learning and development (pp. 239-254). Hillsdale, NJ: Erlbaum. 
Garner, R., Gillingham, M., \& White, C. (1989). Effects of "seductive details" on macroprocessing and microprocessing in adults and children. Cognition and Instruction, 6, 41-57. http://dx.doi.org/10.1207/s1532690xci0601_2

Harp, S. F., \& Maslich, A. A. (2005). The consequences of including seductive details during lecture. Methods and Techniques, 32 (2), 100-103.

http://dx.doi.org/10.1207/s15328023top3202_4

Harp, S. F., \& Mayer, R. E. (1997). The role of interest in learning from scientific text and illustrations: On the distinction between emotional interest and cognitive interest. Journal of Educational Psychology, 89(1), 92-102. http://dx.doi.org/10.1037//0022-0663.89.1.92

Harp, S. F., \& Mayer, R. E. (1998). How seductive details do their damage: A theory of cognitive interest in science learning. Journal of Educational Psychology, 50, 414-434. http://dx.doi.org/10.1037//0022-0663.90.3.414

Izard, C. E., \& Ackerman, B. P. (2000). Motivational, organizational, and regulatory functions

of discrete emotions. In M. Lewis \& J.M. Haviland-Jones (Eds.), Handbook of emotion,

Vol. II (pp. 253-264). New York: Guilford.

Kane, M. J., Bleckley, M. K., Conway, A. R. A., \& Engle, R. W. (2001). A controlled-attention view of working-memory capacity. Journal of Experimental Psychology: General, 130, 169-183.

Kintsch, W. (1980). Learning from text, levels of comprehension, or: Why anyone would read a story anyway. Poetics, 9, 87-98. http://dx.doi.org/10.1016/0304-422x(80)90013-3

Koch, C., \& Laurent, G. (1999). Complexity and nervous system. Science, 284, 96-98. http://dx.doi.org/10.1126/science.284.5411.96

Kuhn, T. (1996). The structure of scientific revolutions ( $3^{\text {rd }}$ ed.). Chicago: University of Chicago Press. (Original work published 1962)

Lehman, S., Schraw, McCrudden, M. T., \& Hartley, K. (2007). Processing and recall of seductive details in scientific text. Contemporary Educational Psychology, 32, 569-587. http://dx.doi.org/10.1016/j.cedpsych.2006.07.002

Mayer, R. E. (2001). Resisting the assault on science: The case for evidence-based reasoning in educational research. Educational Researcher, 30, 29-30. http://dx.doi.org/10.3102/0013189x030007029

Mayer, R. E. (2005). Principles for reducing extraneous processing in multimedia learning: Coherence, signaling, redundancy, spatial contiguity, and temporal contiguity principles. In R. E. Mayer (Ed.). The Cambridge Handbook of Multimedia Learning (pp. 183-200). Cambridge. MA: Cambridge University Press. 
Mayer, R. E., Griffith, E., Jurkowitz, I. T. N., \& Rothman, D. (2008). Increased interestingness of extraneous details in multimedia science presentation leads to decreased learning. Journal of Experimental Psychology, 14, 329-339. http://dx.doi.org/10.1037/a0013835.supp

McCrudden, M. T., \& Corkill, A. J. (2010). Verbal ability and the processing of scientific text with seductive detail sentences. Reading Psychology, 31, 282-300. http://dx.doi.org/10.1080/02702710903256486

Moreno, R., \& Mayer, R. E. (2000). A coherence effect in multimedia learning: The case for minimizing irrelevant sounds in the design of multimedia instructional messages. $\begin{array}{lllll}\text { Journal of } & \text { Educational } & \text { Psychology, } & 92, & \text { 117-125. }\end{array}$ http://dx.doi.org/10.1037//0022-0663.92.1.117

Muller, D. A., Sharma, M. D., \& Reinmann, P. (2008). Raising cognitive load with linear multimedia to promote conceptual change. Science Education, 92(2), 278-296. http://dx.doi.org/10.1002/sce.20244

Paas, F., Renkl, A., \& Sweller, J. (2003). Cognitive load theory and instructional design: Recent developments. Educational Psychologist, 38, 1-4. http://dx.doi.org/10.1207/s15326985ep3801_1

Park, B., Moreno, R., Seufert, T., \& Brunken, R. (2011). Does cognitive load moderate the seductive details effect? A multimedia study. Computers in Human Behavior, 27, 5-10. http://dx.doi.org/10.1016/j.chb.2010.05.006

Rey, G. D. (2012). A review of research and a meta-analysis of the seductive detail effect. Educational Research Review, 7, 216-237. http://dx.doi.org/10.1016/j.edurev.2012.05.003

Sanchez, C. A., \& Wiley, J. (2006). An examination of the seductive details effect in terms of working memory capacity. Memory \& Cognition, 34(2), 344-355. http://dx.doi.org/10.3758/bf03193412

Schnotz, W., \& Bannert, M. (2003). Construction and interference in learning from multiple representations. Learning and Instruction, 13, 141-156. http://dx.doi.org/10.1016/s0959-4752(02)00017-8

Shen, B., McCaughtry, N., Martin, J., \& Dillion, S. (2006). Does “ Sneaky Fox” facilitate learning? Examining the effects of seductive details in physical education. American Alliance for Health, Physical Education, Recreation and Dance, 77, 498-506. http://dx.doi.org/10.1080/02701367.2006.10599384

Tabachnick, B. G., \& Field, L. S. (2006). Using multivariate statistics (5 ${ }^{\text {th }}$ ed.). Boston: Allyn \& Bacon.

Towler, A., Kraiger, K., Sitzmann, T., Overberghe, C. V., Cruz, J., Ronen, E., \& Stewart, D. (2008). The seductive details effect in technology-delivered instruction. Performance Improvement Quarterly, 21, 65-86. http://dx.doi.org/10.1002/piq.20023 


\section{Macrothink}

Journal of Studies in Education ISSN 2162-6952 2014, Vol. 4, No. 3

Wiley, J. (2003). Cognitive and educational implications of visually-rich media: Images and imagination. In M. Hocks \& M. Kendrick (Eds.), Eloquent images: Writing visually in new media (pp. 201-218). Cambridge, MA: MIT Press.

Wright, P., Milroy, R., \& Lickorish, A. (1999). Static and animated graphics in learning from interactive texts. European Journal of Psychology of Education, 14(20), 203-224. http://dx.doi.org/10.1007/bf03172966 